\title{
Producing heavy weight lambs for export
}

\section{GWYN WILLIAMSON Kumu Kumu, R.D.10, Masterton}

\section{Introduction}

My wife, Lindy, and I are the operating managers on Kumu Kumu, a 724 ha sheep and beef property situated $23 \mathrm{~km}$ east of Masterton. Kumu Kumu was purchased in 1988 by a partnership, which in turn is jointly and equally owned by two equity entities, one of which represents the interests of my family.

The property is predominantly hill country straddling both sides of the Maungaraki limestone ridge, the westfacing slopes being exposed to dry north-west winds, and the east-facing being less affected, but both aspects, being loess-covered siltstones, are prone to some erosion. At the base of these hills to the east, we have a reasonable area of alluvial loam flats which are prone to winter wetness, but give high spring/summer production.

In general, we have a breeding ewe flock, retaining our own replacements with a finishing operation producing 1000 lambs on contract for a specific market. We also have cattle, which includes both purchasing weaner Friesian and Hereford/Friesian $\mathrm{X}$ bulls finished to slaughter by 18 months of age, and also purchasing 18-month beef steers to finish to slaughter within 12 months at $300+\mathrm{kg} \mathrm{CW}$. It is our intention to alter our winter sheep/cattle ratio to that of approximately a 75/ 25 mix, and retain a stocking rate of about 12 su/ha.

Our stock numbers as at 30 June 1993 were as follows:

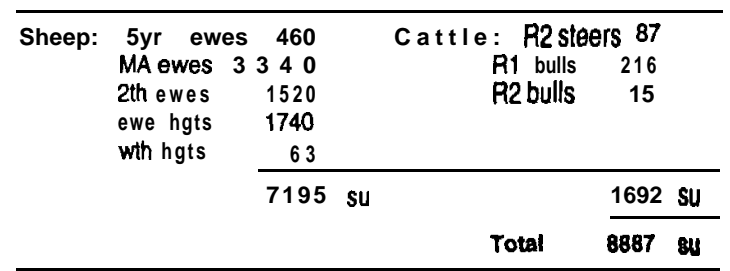

As our development programme unfolded, we found it easier to implement physical improvements to the property, but had some difficulty achieving a corresponding lift in stock performance. This dilemma made it imperitive that we investigate any opportunity that may enhance our livestock sales prospects. Quite simply, we had an immense resource in the form of the ewe flock, albeit underproducing, which I felt offered the most potential because, firstly, it was on hand, and, secondly, any improvements need not involve any high capital inputs. Thus, we looked at lamb marketing options.

\section{Lamb marketing}

Why focus on lambs? To us it was a matter of better selling a scarce resource to stay in business. At the time, 1989190 season, two enterprising local farmers investigated, identified and sought approval to trial market lamb on the west coast of the USA. Fired with high ambition and unbounded enthusiasm, they proceeded to align themselves with farmers prepared to risk some capital and a willingness to supply lambs. Simply, the aim was to increase returns to the farmer by marketing direct to the final consumer.

We felt we could afford any apparent risks: local lamb returns were nothing startling and we could actively participate to lift lamb returns.

Market research identified an opportunity/niche (more likely with hindsight it was a hairline crack in the granite of the US gourmet market) for lamb. Above all else this very sophisticated and yet complicated consumer-orientated market could be "cracked" if, and only if, the three marketing maxims were recognised and adhered to. They are Orders must be supplied in full, on time and to specification.

We understood the first two requirements, but what did the specifications entail? In general terms what was required was a large lean spring lamb, raised and processed in the cleanest and environmentally friendliest conditions possible, cut into specialty cuts packaged so that upon removal the product is ready for display/use, delivered yesterday in a fresh or chilled state, Simple, only 14000 miles separates us!

Back in New Zealand, how do these specifications influence production? The simple answer is - greatly. Therefore, to be successful we must produce to order and avoid any notion of a disposal mentality. Thus we now begin to instill some production disciplines,

whereby only carcasses meeting the following conditions are dispatched. The minimum carcass weight is $18 \mathrm{~kg}$ with allowable fat levels of $4-14 \mathrm{~mm}$ at the GR point. Carcasses must also meet certain health status protocols. 


\section{Lamb selection}

Ideally, having decided to supply, we commit ourselves to a supply contract to enable an orderly flow of animals to processing, as and when they meet specification.

Obviously breeding has an important role to play, but so too has timing of events like lambing dates, weaning and feeding regimes. It could be argued that suitable stock can be identified within any breed, and therefore most selection occurs at weaning. This is the first opportunity to make a tangible choice of the particular animals one wishes to grow on. Our selection is based firstly on the lamb in the upper weight range, exhibiting good body length and height (coincidently, we select our rams on weaning weight indices and visual body length). We also find that by treating all male lambs in a similar fashion at docking, i.e., as cryptorchids or wethers, selection is further simplified. Thus we find that if we need 1000 lambs we retain up to 1500 from which to select further, while the residue of the lamb crop we try to sell as best we can as soon as practicable. This is important, as the contracted lambs need every opportunity to enable them to grow to their greatest potential as early as possible in case there is a drought, and also, during hot conditions in January/ February, growth rates decline markedly. By concentrating on producing lambs to heavy weights, management input also has to increase to ensure goals are achieved. This can be illustrated by both the national and our own average carcass weights being in the vicinity of $14.5 \mathrm{~kg}$ before concentrating on heavy lamb production. This discipline has to be learned.

In general, we aim to supply lambs on a consistent basis from late February until August. To facilitate this spread, growth weights and fat covers are constantly monitored to avoid overfats in particular and to optimise feed utilisation.

\section{Production}

To achieve high production standards, planning is done long before the lambs hit the ground. We have identified the need for a farm within a farm approach so that our capital stock is not penalised in the quest to meet targets with the trading stock, i.e., contract lambs and bulls. Therefore, we have had to also intensify the portion of the farm allocated to breeding stock. This has been done by electric fence subdivision, strategic applications of DAP and intensive winter rotations of $\mathbf{8 5 +}$ days for each of the two mobs of ewes, with the intention of maximising ewe performance and liveweight, which in turn is hopefully reflected in the enhanced weaning weights of the lambs. We aim for an average weaning liveweight of $30+\mathrm{kg}$ by mid November, and at this stage the lambs are drafted into mobs suitable for grazing either Puna chicory, fescues, ryegrasses or brassicas.

We also recognise that our area is prone to dryness and have thus embarked upon an intensive pasture improvement programme with drought-tolerant species of grasses, bromes and herbs. We have a potential conflict of interests during extreme dryness because the limited area available to feed silage to the ewe flock is the area on which we accommodate the trading stock. The intention has been and still is to regrass 10 15 ha per year, encompassing both flat land and easy hill under both full cultivation and minimum tillage techniques.

We have achieved some very pleasing growth rates on fescue-based pastures and some spectacular growth rates on chicory that encourage us to further develop our pastures. A good lesson learnt is that in this endeavour, one only reaps from that which you sow.

At this stage no attempt has been made to quantify the necessary returns to the producers to justify the effort and commitment involved, as artificial factors have unduly influenced pricing this season, Nevertheless, the following table illustrates the date of supply, grading, carcass weights and returns.

\begin{tabular}{|c|c|c|c|c|c|}
\hline Date(1993) & Number & Weight & Graded & DNG & $\$$ \\
\hline $\begin{array}{l}18 / 3 \\
2 / 4\end{array}$ & $\begin{array}{r}108 \\
63\end{array}$ & $\begin{array}{l}17.6 \\
19.5\end{array}$ & " & . & $\begin{array}{l}45.10 \\
46.60\end{array}$ \\
\hline $2 / 4$ & 7 & 16.2 & & . & 39.41 \\
\hline 2314 & $\begin{array}{r}101 \\
47\end{array}$ & $\begin{array}{l}19.5 \\
17.6\end{array}$ & . & . & 51.27 \\
\hline $\begin{array}{l}23 / 4 \\
14 / 5\end{array}$ & $\begin{array}{l}41 \\
42\end{array}$ & $\begin{array}{l}11.6 \\
19.5\end{array}$ & •. & & $\begin{array}{l}44.21 \\
49.16\end{array}$ \\
\hline $14 / 5$ & 8 & 20.3 & & $t$ & 36.07 \\
\hline $21 / 5$ & 172 & 19.4 & - & & 46.72 \\
\hline $21 / 5$ & 26 & 17.4 & & ' & 45.86 \\
\hline $15 / 6$ & 4 & 20.3 & & . & 56.63 \\
\hline $15 / 6$ & 15 & 21.1 & & ! & 45.14 \\
\hline 1516 & 16 & 21.1 & • & & 57.92 \\
\hline $15 / 6$ & 47 & 20.9 & • & & 57.56 \\
\hline $6 / 7$ & 19 & 21.9 & • & & 56.01 \\
\hline $6 / 7$ & 161 & 20.7 & - & & 56.45 \\
\hline \multirow{3}{*}{$9 / 7$} & 59 & 21.9 & • & & 60.34 \\
\hline & 897 & & 680 & 217 & \\
\hline & & Avge & $\$ 52.98$ & Avge & $\$ 48.92$ \\
\hline
\end{tabular}

\section{Conclusion}

To produce heavy weight lambs to exacting specifications is both a challenge and a learnt discipline that should enhance profitability, and not overshadow other equally important facets of the farming business.

This venture graphically illustrates the need for greater awareness of consumer needs, and how production from conception to consumption is determined, not by procurement, but a closer association with the market place. 